\title{
AN INVESTIGATION OF SOME ASPECTS OF STUTTERING-LIKE SPEECH IN ADULT DYSPHASIC SUBJECTS
}

\author{
LESLEY CAPLAN, B.A. (SP. \& H. TH.) (Witwatersrand) \\ Speech Therapy Department, Groote Schuur Hospital, Cape Town
}

\begin{abstract}
SUMMARY
Some dimensions of stuttering-like symptoms of five dysphasic patients were considered and compared to several aspects of stuttering which are generally well-known and documented.
\end{abstract}

The nature and amount of the dysfluencies of dysphasia were examined, and, although the amount of non-fluency appeared to justify the label of stuttering, the nature of the dysfluencies was much like that observed in normal speakers and not that considered to be the distinguishing features of stuttering. The loci of the dysfluencies in the sequence of dysphasic speech were investigated and the majority of subjects were found to experience more difficulty on the function words of language rather than on the content or lexical words which precipitate dysfluency in stutterers. All subjects experienced the greatest difficulty on words in the initial position in the sentence as is found with stutterers. For most of the subjects the frequency of dysfluency was highest on longer words and it was observed that subjects generally experienced more difficulty on consonants than on vowels. Under conditions of propositionality it seemed that there was some increase in the frequency and severity of the dysfluencies of dysphasics while the adaptation task yielded divergent results.

\section{OPSOMMING}

Sommige aspekte van simptome, soortgelyk aan hakkel, by vyf disfasiepasiënte, is met verskeie algemeen bekende en reeds bewysde kenmerke van hakkel vergelyk. Die aard en hoeveelheid onvlothede van die disfasie-pasiënte is ondersoek en alhoewel die hoeveelheid onvlothede die kenteken van hakkel regverdig, was die aard van die onvlothede in 'n groot mate soortgelyk aan die onvlothede wat by normaalsprekendes voorkom. Die onvlothede is dus nie verwant aan die onderskeidende kenmerke van hakkel nie.

Die spesifieke posisie van onvlothede in die opeenvolging van die spráak van disfasie-pasiënte is ondersoek. Die meerderheid van die proefpersone het groter probleme op funksiewoorde van die, taal ondervind en nie soseer probleme gehad met die inhoud of leksikale woorde soos hakkelaars nie. Soos gevind by hakkelaars, het al die proefpersone die grootste mate van moeilikhede ondervind met woorde in die inisiële posisie van die sin. Die frekwensie van die onvlothede was ook hoër by die meerderheid van die proefpersone. Daar is ook waargeneem dat daar oor die algemeen meer probleme op konsonante as op ander woorde ondervind word. Dit het voorgekom asof 'n toename in die frekwensie en erns van die onvlothede by die disfasie-gevalle ontstaan onder toestande van proposisionering, terwyl die aanpassingstaak uiteenlopende resultate gelewer het. 
In many instances in the literature mention has been made of brain-injured adults, who have stuttering-like speech. Various authorities cite cases of aphasia showing symptoms suggestive of stuttering and make reference to the repetition of sounds and syllables, hesitancies and the use of superfluous words accompanied by tension, in dysphasic speech. In attempting to explain the association of stuttering and aphasia writers have provided phrases such as "dysphasia with stuttering" (Oltuszewski), "aphatic stuttering" (Kussmaul), and "stuttering in aphasia" (Froeschels)1.

Various pathologies of the central nervous system like Parkinsonism, the extrapyramidal dysarthrias, as well as a number of pyramidal and cortical dysarthrias present symptoms that resemble stuttering - retarded rate of speech utterance that may be irregular and jerky, defective intonation, and a tendency towards perseveration where there may be a difficulty in the production of initial sounds ${ }^{3,6}$.

In considering the field of stuttering etiology and symptomatology, theories and descriptions are in conflict with each other. It was St. Onge ${ }^{20}$ who recommended the use of the "syndrome" concept to distinguish different types of stutterers in an attempt to eliminate some of this confusion. He propounded an approach directed towards isolating the particular symptoms of stuttering into consistent and meaningful entities, rather than viewing the disorder indiscriminately, as a mixture of psychological, motor and other signs. He suggests the separation of stutterers into three groups.

i) The stutterer with no indication of constitutional or psychogenic symptoms, who simply manifests a phobia about speech.

ii) The psychogenic stutterer who employs stuttering as a symptom in a more extensive disturbance.

iii) The organic stutterer who manifests intolerance of non-fluency as a result of some structural abberation.

It is this last alternative that bears relevance to the present study.

In reviewing the literature on stuttering, various authorities have put forward a concept of stuttering as a sub-clinical aphasia. Travis ${ }^{21}$ expounded a theory of cerebral dominance, Karlin ${ }^{12}$, a psychosomatic theory of a delay in myelinization, West ${ }^{25}$ wrote of stuttering and epilepsy and Eisenson ${ }^{7}$, a perseverative theory that stressed a neurological basis for stuttering.

Attention has been briefly focused above on these writers in the field of aphasia who make reference to stuttering-like symptoms, and, on authorities in the field of stuttering who, in turn, stress neurological factors. Mention should also be made of the research by Goldman-Eisler and others who have shown that normal speakers too, manifest dysfluency at specific loci in the speech sequence and that this dysfluency is an integral part of the speech process $^{2,22}$.

It seems pertinent then to question and consider the relationship between stuttering and aphasia. One may approach this from the etiological point of view, but in this study, the writer has chosen to examine symptomologically 
some dimensions of the stuttering-like speech of dysphasics, and to compare them with some dimensions of stuttered speech as reported in the literature.

\section{METHOD}

An attempt will be made to examine the repetitive pattern of dysphasic speech in terms of the amount and nature of dysfluency; further, the loci of dysfluencies in the sequence of dysphasic speech will be investigated.

An attempt will also be made to determine whether the dysfluencies of dysphasia are susceptible to the influences that bring about changes in stuttering behaviour. It is hypothesized that under conditions of propositionality, i.e. where communicative stress and meaningfulness of the presenting situation is increased, dysphasics will show an increase in the frequency and severity of dysfluency, while on the adaptation task where there are repeated sayings of the same phrases, a reduction of stuttering symptoms will manifest itself.

\section{Subjects}

Five adult aphasic patients, three males and two females were used as experimental subjects, one male and one female being Afrikaans speaking. All subjects were classified by their speech therapists as predominantly expressive aphasics ${ }^{23}$, who were able to communicate spontaneously and meaningfully. An important criterion for selection was that the subjects should manifest some degree of non-fluency in their speech. The subjects also showed a variety of specific language disturbances, the most notable being anomia and apraxia. The subjects ranged in age from 41 to 62 years.

No experimental group of stutterers was used as the symptomotology and the modification of stuttering behaviour has been extensively documented.

\section{Procedure}

(a) Spontaneous Speech Samples. Johnson ${ }^{10}$ indicates that taperecorded samples of speech from adults can be obtained by using the "Job" task, where the subject is encouraged to talk for 2-3 minutes on his chosen, likely or future vocation. A modification was introduced, in view of the emotionality of some subjects as regards their occupations, and topics such as daily activities, hobbies, family set-up and in some cases, vocations were suggested.

To obtain a second speaking sample, a picture from the Thematic Apperception Test (TAT) was used. Johnson ${ }^{11}$ suggested the use of Card No. 10 of the TAT where the subject is asked to tell a story based on the picture, and points out that although the TAT task might be more emotionally loaded than the "Job" task, the type of speech samples elicited are very similar.

The spontaneous speech samples were used, to provide data on the nature and amount of dysfluency and the loci of dysfluencies in the sequence of dysphasic speech: Spencer Brown ${ }^{6}$ was probably the most prominent 
investigator in this field. He isolated four factors that he felt precipitate stuttering. He postulated that the grammatical function of words, their position in the sentence, the length of words and the phonetic characteristics of the initial sounds of the words, were important in evoking stuttering. It seems interesting to determine whether these factors are also important in accounting for the dysfluencies of dysphasia.

(b) Propositional Speech Sample. In view of the fact that propositionality appears to be a factor common to both aphasia and stuttering ${ }^{7,9}$ and because various authorities, particularly Eisenson ${ }^{7}$, have drawn attention to the variability and inconsistency of stuttering and related it to the degree to which the stutterer is attempting to convey meaning, it was important to include this phenomenon in the experimental design.

A test was devised to produce conditions of propositionality. It was based partly on an idea put forward by Newman ${ }^{16}$ in his article on adaptation in self-formulated speech and partly on a procedure being used by the Department of Phonetics and General Linguistics in collaboration with the Engineering Faculty at the University of the Witwatersrand ${ }^{13}$ in teaching engineering students the art of communication.

The task involves the recorded description of an arrangement of geometrical figures (Fig. 1). The drawing used was based on the series of figures Lanham ${ }^{13}$ described in his course for engineering students. The subjects were instructed as Newman ${ }^{16}$ suggested to describe the drawing in such a way that a listener could make an accurate reproduction of the figure solely on the basis of the recorded directions. To increase communicative responsibility, it was pointed out that the recording would be played to first year students to determine their ability to follow directions.

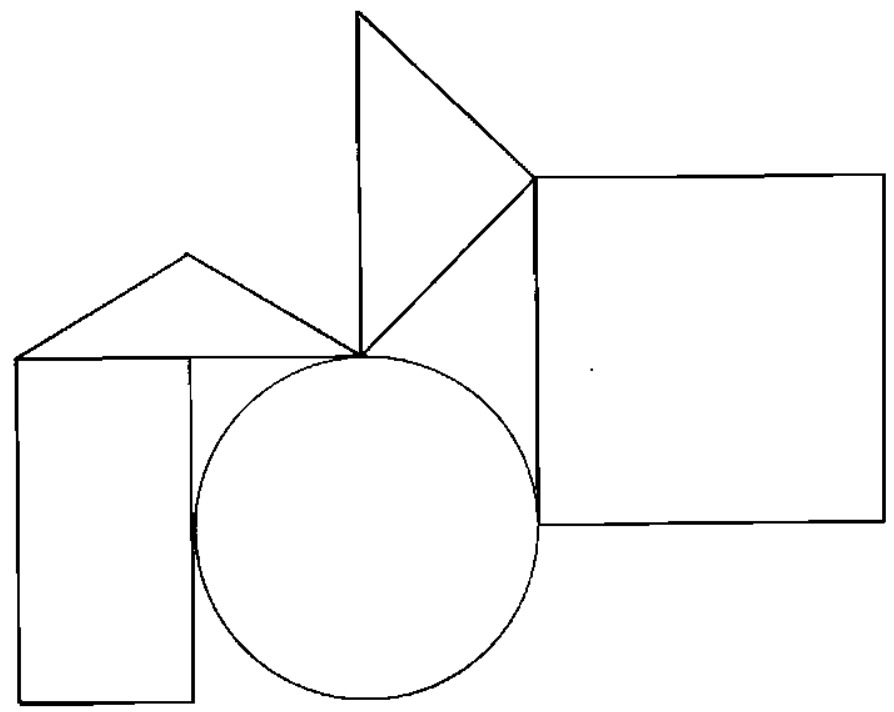

Figure 1. Diagram used to Elicit a Propositional Speech Sample. 
(c) Adaptation Task. A definition of adaptation relevent to this study is one postulated by Schaef ${ }^{19}$, where he considers adaptation as ".... the reduction of the frequency of the stuttering response with repeated and continued elicitation of verbal behaviour under constant stimulus conditions".

In response to St. Onge's ${ }^{20}$ plea for the differentiation of stutterers into various clinical syndromes, Newman ${ }^{16}$ postulates the use of the adaptation effect as a "discriminating tool". This provides then, a rationale for the employment of this phenomenon. It seems that an indication of the adaptation trends of aphasic patients may well provide a model of the adaptation trend to be expected in the organic stutterer.

In this study adaptation was determined in two ways. In the first, a questionand-answer technique devised by Schaef ${ }^{19}$ for stutterers was used. Five questions were asked, and each question had to be answered using the stem of the question in the answer; e.g. "What city is this?" "This city is ...........". Five questions constituted one trial, and each subject was given three consecutive trials, where the same questions were asked and the same answers given. The second involved repetition of five sentences selected from "Arthur the Young Rat" on three consecutive trials"1. The number of sentences was arbitrarily selected on the basis of the assumed capabilities of the most severe aphasic subject.

(d) Analysis of the spontaneous speech sample. A 150-word segment of speech was selected from the spontaneous speech sample elicited by using Johnson's "Job" and TAT tasks. The criteria for selection of the 150-word segment were that the particular segment should not be interrupted by any unduly long pauses and that it should comprise portions of both the "Job" and TAT tasks.

This 150-word segment was analysed in terms of the following factors:-

The Nature of the Dysfluencies. The dysfluencies were identified and categorized from a transcript made of the relevant segments of the speech sample. The categories were those suggested by Johnson ${ }^{10}$ and are: interjections of sounds, syllables, words and plirases; part-word repetitions; word repetitions; phrase repetitions; revisions: incomplete phrases; broken words; prolonged sounds.

The Severity of the Dysfluencies. For this purpose three measures were used:

i) The rate of utterance: This dimension was chosen because it is considered to be a measure of stuttering independent of listener evaluations and, therefore, one of the most objective methods available. It is computed in words per minute and represents the ratio of verbal output to speaking time ${ }^{10,11}$.

ii) A rating scale of the severity of dysfluency was used. Experimentation has shown that a 9-point equal-appearing interval scale of severity can have internal consistency and is reliable 27 . Three judges who were practicing speech therapists, rated the severity of the dysfluencies.

iii) The frequency of stuttering as computed of the Total Dysfluency Index also gave some indication of the severity of the dysfluencies in the 
speech samples. This represents the most comprehensive dysfluency analysis where all dysfluencies in the speech sample are identified, classified and tabulated. The sum of the category index constitutes this measure. The following formula was used for the computation:

$$
\text { TDI }=(\mathrm{n} / \mathrm{A}) 100
$$

where $\mathrm{n}=$ total number of dysfluencies, and $\mathrm{A}=$ verbal output ${ }^{11}$.

\section{The Loci of the Dysfluencies.}

i) Grammatical function of Words: Having analysed the nature and type of the dysfluencies in the speech sample, every word that was considered to be dysfluent was tabulated in terms of its grammatical function in the speech sequence. The parts of speech considered were nouns, verbs, adjectives, adverbs, articles, prepositions, pronouns and conjunctions. In addition the total number of each of these parts of speech in the sample was enumerated, e.g. the number of dysfluent nouns was determined as well as the total number of nouns in the speech sample, and the ratio of dysfluent nouns to the total number of nouns was presented as a percentage.

ii) The Phonetic factor: Again having tabulated all the dysfluent words as described above, the initial sounds were tabulated and the percentage of words beginning with a particular sound out of the total number of words beginning with that sound in the speech sample, was computed.

The total number of dysfluent consonants and the total number of dysfluent vowels were counted and represented a percentage of the total number of consonants and vowels in the entire speech sample for each subject respectively.

iii) Position of word in the sentence: The position of the words identified as dysfluent in the sentence was determined. The total number of words that occurred first, second, third etc; in the sentences in the speech sample were also counted in order to find out what percentage of the first, second, third etc., words in the sentences were dysfluent.

iv) Word Length: The same procedure as described above was applied in the investigation of this factor. Again the length of each dysfluent word was determined and the number of words of a particular length were coupled as a percentage of the total number of words of that particular length in the entire speech sample.

(e) Analysis of the Adaptation Task. The responses obtained, employing the question-and-answer technique ${ }^{19}$ and repetitions of sentences from "Arthur the Young Rat" were subjected to frequency counts. The number of words considered to be dysfluent on the first, second and third trials were numbered and presented as a percentage of the total number of words uttered in each trial. Adaptation was computed using the following formula:

$$
(a-b) / a
$$

where $a$ and $b$ were the number of words identified as dysfluent on trials one and two, for example. 
(f) Subjective comments by judges on the speech samples. Prior to being asked to rate the severity of dysfluencies in the speech samples, the judges were asked to "comment on" the speech samples. The judges were completely unaware of the objectives of this study project and unfamiliar with the subjects used in the study. The comments were considered in terms of what the judges believed the speecl problems of the subjects were.

\section{RESULTS AND DISCUSSION}

An attempt will be made to discuss any of the similarities or differences found in the responses of dysphasics when compared with the findings on stuttering as presented in the literature.

\section{The Amount, Nature and Loci of Dysfluencies.}

The data for the amount of the dysfluencies of dysphasia and their nature were obtained from the sample of spontaneous speech. It is interesting to note the total dysfluency index for each subject and to compare this with the norms given by Johnson ${ }^{11}$ in determining whether or not the amount of dysfluency justifies labelling the aphasic "a stutterer". Despite the wide range of dysfluencies nanifested by both stutterers and non-stutterers, it seems that three of the five subjects in this study could possibly have been considered stutterers. (Table 1). However the nature of the dysfluency in dysphasic speech and the nature of stuttering appear to differ. In order to identify the dysfluencies in the speech of the dysphasics and to differentiate them from moments of stuttering, the eight categories suggested by Johnson ${ }^{10}$ were employed.

\begin{tabular}{|c|c|c|c|c|c|c|}
\hline Sut & jects & S1. & $S 2$. & S3. & $S 4$. & S5. \\
\hline Total D & $\begin{array}{l}\text { sfluency } \\
\text { dex }\end{array}$ & 34 & 16 & 27,33 & 14 & 38,67 \\
\hline NATURE & $\begin{array}{l}\text { Inter- } \\
\text { jections }\end{array}$ & 16 & 5,3 & 11,33 & 3,33 & 18 \\
\hline & $\begin{array}{l}\text { Part-word } \\
\text { repetition }\end{array}$ & 4 & ,67 & 1,33 & 1,33 & 7,33 \\
\hline $\begin{array}{c}\text { THE } \\
\text { DYSFL UEN }\end{array}$ & $\begin{array}{c}\text { Word } \\
\text { Repetition }\end{array}$ & 3,33 & 2,67 & 9,33 & 1,33 & 6,67 \\
\hline CIES & Revisions & 4,6 & 3,33 & 1,33 & 2 & 3,33 \\
\hline
\end{tabular}

Table I. Percentage of Dysfluencies and the Nature of Dysfluencies in a 150-word sample of the Speech of Dysphasic Subjects. 
All subjects manifested the greatest number of dysfluencies in the category of interjections. The dysfluencies categorized as word-repetitions, part-word repetitions, and revisions also occurred frequently, and to a much lesser extent than interjections (Table 1). It is important to note that the disorder of stuttering encompasses much more than moments of dysfluency and that dysfluency per se does not constitute the whole of the problem known as stuttering ${ }^{11}$.

In view of the information already cited, it appears that the non-fluencies shown by the subjects in this experiment are similar to the non-fluencies exhibited by normal speakers, and not those considered to be the distinguishing features of stuttering ${ }^{10}$.

From the results then, two apparently conflicting aspects emerged, and in order to determine whether the aphasic subjects did, in fact, appear to "sound" like stutterers, three judges were invited to comment on the speech samples. As mentioned, these judges were qualified speech therapists who were not aware of the speech and language problems of the subjects nor of the objectives of this study. The judges drew attention to patterns such as hesitancy and repetitions in speech, use of interjections as anti-expectancy devices, circumlocutions as well as manifestations of anxiety and tension. Generally it seems, that on the basis of trained listener evaluations, symptoms that have been regarded as peculiar to dysphasia, (anomia, incomplete sentences, sequencing difficulties) can be re-interpreted and viewed within the framework of stuttering behaviour. It seems plausible that other factors (apart from those mentioned) like anxiety and tension, as well as disturbances in spontaneity of expression, could be significant in contributing to the evaluation of stuttering.

The amount of dysfluency manifested by the subjects appeared to justify the label of stuttering while the nature of the dysfluencies seem to be that revealed in the speech of normal speakers and not that which many authorities consider to be the distinguishing features of stuttering. Despite this, the findings should not be considered an impasse and the comments of the judges in evaluating the speech as stuttered speech emphasizes this point. It appears that here are other more subtle attributes of the dysfluencies that contribute to the diagnosis of stuttering.

The sample of spontaneous speech obtained in the "Job" and TAT tasks yielded the data for the analysis of the loci of dysfluencies.

The Grammatical function of Words. The majority of subjects produced results contrary to those expected from stutterers. More difficulty was experienced in the function words of language (prepositions, articles, pronouns and conjunctions) rather than on the content or lexical words (nouns, adjective, adverbs, and verbs).

The postulate that stuttering tends to occur on those words that are focal points in the speech sequence, i.e. where the transmission of meaning is most important, and where the speaker's emphasis and the interest of the listener is concentrated, is not demonstrated by the findings with the dysphasic cases in this study. 
It is interesting to examine these results in relation to the data on the loci of stuttering in the speech sequence of primary stutterers, as reported in the literature. Bloodstein ${ }^{2}$ indicates that in Phase 1 stutterers, stuttering occurs on the "small" parts of speech - the pronouns, conjunctions and prepositions - and a modification occurs with the development of stuttering. It is precisely on these "small" parts of speech that the dysphasic subjects had difficulty.

Weiss's ${ }^{24}$ concept of central language imbalance, or cluttering, is also worth considering as it seems that the initial stage of stuttering and that of cluttering have been described as identical and that the development of this "imbalance in speech" into stuttering is dependent on the reactions of the individual to the primary disorder. It is possible, therefore, to assume that in dysphasia there is a situation comparable with the postulated undifferentiated primary stages of stuttering and cluttering.

Word Length. In considering the effect of word length (as calculated by number of letters) on the frequency and severity of dysfluencies in dysphasic speech, the greatest frequency of occurrence of dysfluencies was found on the longer words for four of the five subjects: Dysfluencies occurred $100 \%$ of the time on the longest words and for one subject the second longest word elicited the most dysfluency. These results were confounded to some extent, by the occasional occurrence of severe dysfluency on short words and minimum dysfluency on longer words. Wingate ${ }^{26}$ has explained the finding that longer words tend to evoke more dysfluency, in terms of the fact that longer words involve a more intricate pattern of motor co-ordination. This has neurological implications.

Position of the word in the sentence. The most prominent characteristic of the data here, is the fact that all five subjects showed the greatest frequency of dysfluency on the words in initial position in the sentence. The percentage of dysfluency on initial words was $27 \%$ in one case, $16 \%$ in another, and in three of the cases at least $10 \%$ greater than the scores obtained on the words in other positions. These results approximate those observed in stuttering, where there is "a gradient of stuttering increasing with proximity to the initial words". (Quarrington, Conway \& Siegel ${ }^{17}$ ).

The Phonetic Factor. In observing the results obtained in determining the influence of the phonetic factor in precipitating dysfluency, it was obvious that this was a markedly variable factor, differing from individual to individual. No particular sound could be determined to precipitate dysfluency, but it was observed that subjects experienced more difficulty on initiál consonants than on initial vowels. This tendency has been described in the literature on stuttering. It seems that consonants involve more tension of the articulators and are more difficult to utter, requiring rather highly organized and co-ordinated movements ${ }^{17}$.

Although a variety of explanations have been offered for the findings as regards the loci of dysfluency, an interpretation that seems to be highly relevant in terms of this study, is one presented by Wingate ${ }^{26}$. In accounting for the fact that word length and position of the word in the sentence are important factors in precipitating dysfluency, Wingate has postulated a 
physiological explanation that might provide some support for the hypothesis that stuttering is a form of apraxia. He indicates that it is the initial sounds that are the focal points of attack and are the points at which the transition from inactivity to "energizing of motor functions" occurs. Further, Luria's ${ }^{15}$ description of an apraxic disturbance is relevant here. He considers that there is a loss in the selectivity of the innervation of the articulatery movements, manifesting itself in an inability, on the part of the patient, to assume the correct position of tongue and lips in the production of speech.

Wingate ${ }^{26}$ has also pointed out that the conspicuousness of the word in the speech sequence is not the most important factor, but that the longer the word, the more intricate the pattern of motor co-ordination required. In addition, the more intricate and complex the movements required of the patient, the more demanding the act of "motor planning" will be and the more inaccessible is the motor schema for that word. These interpretations could well be incorporated in the concepts of ideokinetic and ideational $\operatorname{apraxias}^{5,18}$

The factors of word position, word length and phonetic characteristics do seem to play an important part in precipitating dysfluency in both stuttering and dysphasia, while the grammatical factor revealed what is generally noted in the primary stage of stuttering.

2. Propositional aspects and the adaptation effect were the phenomena investigated in determining whether the dysfluencies of dysphasics are susceptible to influences that bring about modifications in stuttering behaviour.

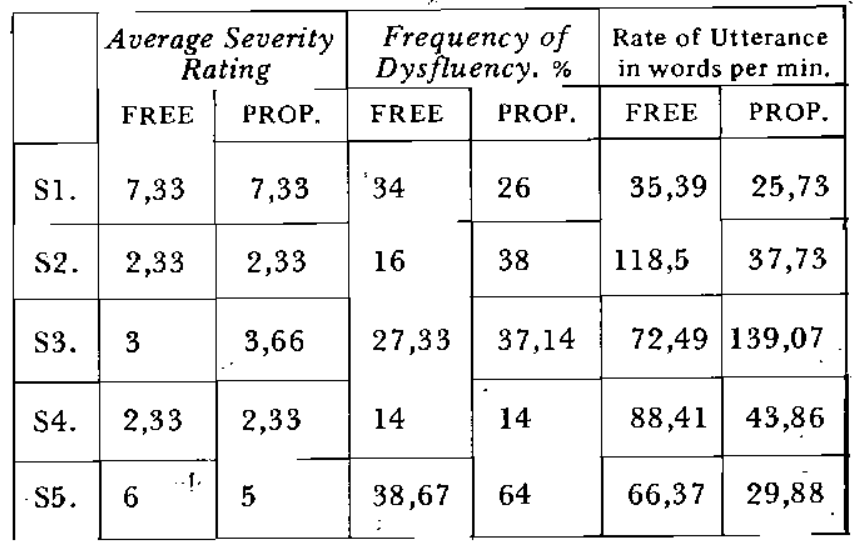

Table II. Comparison of Severity and Frequency, and Rate of Utierance on a 150-word sample of the Free Speech of Dysphasic Subjects and the Propositional Speech Task. 
Propositionality. Three measures were used to determine the effect of propositionality on dysphasic dysfluency. On an equal-appearing interval scale, ratings of the severity of dysfluency showed no change from the free speech sample to the propositional task, while the frequency count also indicated no real change. However, the assessment of the rate of utterance, revealed a reasonably marked reduction in the rate of verbal output under conditions of propositionality (Table 2 ).

The measures used did not reveal a trend in the results, although there is evidence of consistency with individual subjects. Despite the inconclusiveness of these results, it does seem that with more rigorous experimental procedures, there could be an increase in the severity and frequency of dysfluency when subjects encounter a situation in which their ability to propositionalize is focussed upon.

The Adaptation Effect. On the question-and-answer technique devised by Schaef ${ }^{19}$ adaptation scores approximated those found in stutterers. There was a decrease in the frequency of dysfluency from one trial to the next.

On the test requiring repetition of presented sentences from "Arthur the Young Rat" most of the subjects manifested positively accelerated adaptation curves i.e. there was an increase in the frequency and severity of dysfluency on the three consecutive trials involved in the task (Table 3).

It seems that these results can be explained by considering the effects of fatigue on responses of dysphasic patients. The increased fatigue during the second task (three consecutive repetitions of a single sentence) appears to have been greater than that in the first task, because each response on the first task was separated from succeeding responses by a question from the examiner. The subjects were, therefore, given a rest period in which some recovery could have occurred. Goldstein ${ }^{8}$ referred to the evidence of fatigue in brain-damaged patients and he pointed out that fatigue results in manifestations resembling catastrophic responses, and that perseveration is considered by some authorities to be a catastrophic response or an attempt to avoid catastrophe.

It seems then, that in dysphasics, repetition of a response rather than producing an inhibitary potential affiliated to fatigue ${ }^{2}$, results in unobstructed, persisting responses related to fatigue.

The fact that fatigue is a behavioural response, characteristic of stressful situations ${ }^{8}$, and that the factor of stress played a major role in accounting for stuttering in terms of a breakdown theory where there is a failure in the neuromuscular organization of the individual, could account for the increase in the frequency of dysfluency on successive repetitions of the same material. This finding does seem to reject the hypothesis that a reduction of dysfluency will manifest itself in the speech of dysphasics during repeated readings of 


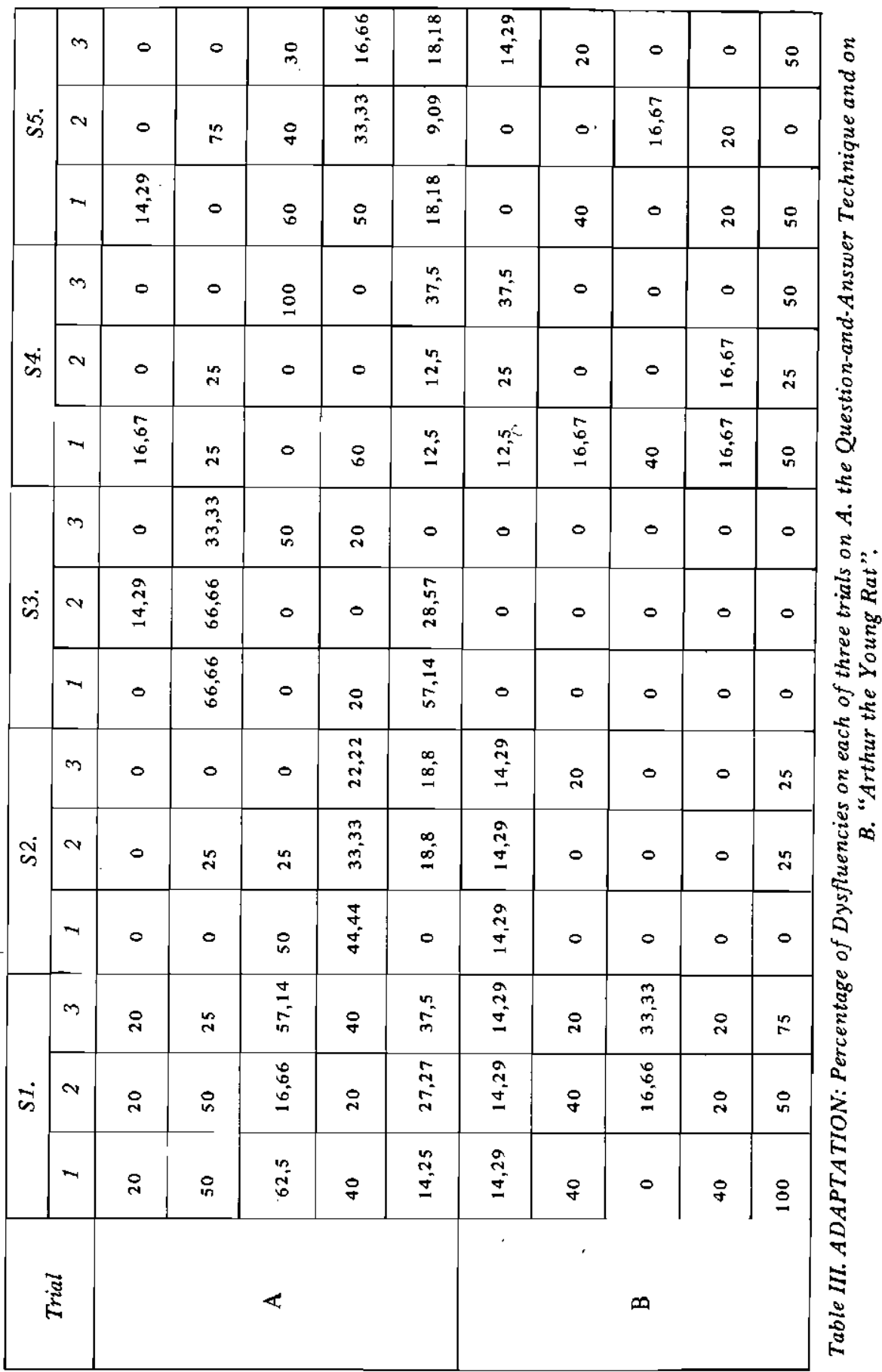


the same material. However, it appears that methods of eliciting adaptation do tend to bias results. Possibly with further experimentation, and with refinements in techniques, the adaptation effect may be revealed to be a potential "discriminating tool" in the investigation of non-fluencies, irrespective of the origin ${ }^{16}$.

\section{CONCLUSION}

As noted above the results of this study appear inconclusive although some trends can be identified. It cannot be said that the dysfluencies of dysphasia are alike or unlike those of stuttering, nor can anything be said as regards the behaviour of these dysfluencies under certain conditions.

The nature and amount of the dysfluency of dysphasia were examined, and although the amount of dysfluency appeared to justify the label of stuttering, the nature of these dysfluencies differs from those observed in stuttering. Despite this, trained judges were inclined to evaluate the speech as stuttered speech and it seems, therefore, that other more subtle attributes of the dysfluencies must be considered as contributing to the diagnosis of stuttering. Possibly anxiety and tension as well as the retardation in the spontaneity of expression, are the operative factors.

The loci of the dysfluencies in the sequence of dysphasic speech were investigated. In terms of the grammatical function of words, the majority of subjects experienced more difficulty on the function words of language, rather than on the content or lexical words which precipitate dysfluency in stutterers. All subjects experienced the greatest difficulty on words in the initial position in the sentence as is found in stutterers. For most of the subjects dysfluency was most frequently prećipitated by longer words and consonants generally created more difficulty than vowels.

In investigating the phenomena that modify stuttering behaviour, propositionality and the adaptation effect were considered. Under conditions of propositionality some increase in the frequency and severity of the dysfluencies of dysphasics was observed, while on the adaptation task divergent results were obtained.

The study has, however, yielded a number of diagnostic, therapeautic and research implications. Possibly one of the most important, and in response to St. Onge's ${ }^{2.0}$ plea for the division of stuttering symptoms into separate syndrome complexes, is the need for differential diagnosis in relation to the problem of stuttering. By knowing what type of dysfluencies predominate and whether the dysfluencies are susceptible to the adaptation effect, and in what way, the clinician may well be provided with a further clue in her attempts to make a differential diagnosis and plan appropriate therapy. In conjunction with other measures, these factors may prove instrumental in determining whether a child's dysfluencies are normal, the result of stressful environmental pressures in an organically normal individual, the overt manifestations of a word-finding difficulty, or symptoms of an inadequate neurophysiological organisation. 
In the treatment of any disorder of speech or language where dysfluencies manifest themselves it may be important, therapeutically to be aware of the factors that are instrumental in determining the occurrence of the dysfluencies and to desensitize the patient to the influences of these factors. Propositionality, it seems, can be considered to be responsible for much of the inconsistency and variability observed in dysphasic and stuttering responses, and the need to heighten the patient's level of tolerance to aspects of this phenomenon and to desensitize him to those factors that precipitate difficulty is important. difficulty is important.

In conclusion this study could possibly be most profitably viewed as a preliminary in the investigation of the stuttering-like symptoms in expressive disorders of any type. Examination of the hesitancies of normal speech, dysphasic and stuttered speech may well provide some data to add to the understanding of the process of language formulation and how it breaks down. Further study along these lines may provide added information as to the nature of stuttering.

\section{REFERENCES}

1. Arend, R., Handzel, L. and Weiss, B. (1962): Dysphasic Stuttering. Folia Phoniatrica, 14; 55-66.

2. Bloodstein, O. (1969): A Handbook on Stuttering. National Easter Seal Society for Crippled Children and Adults, Chicago, Illinois.

3. Brain, R. (1961): Speech Disorders. Butterworths, London.

4. Brown, S.F. (1945): The Loci of Stuttering in the Speech Sequence. J. Speech Dis., 10;181-192.

5. Canter, G.J. (1969): The Influence of Primary and Secondary Verbal Apraxia on Output Disturbances and Aphasic Syndromes. Paper presented to the Annual Meeting of ASHA, Chicago, Illinois.

6. Critchley, M. (1970). Aphasiology and Other Aspects of Language. Edward Arnold (Pub) Ltd., London.

7. Eisenson, J. (1958): A Perseverance Theory of Stuttering. In: Stuttering: A Symposium. Harper and Row Publishers, New York.

8. Goldstein, K. (1948): Language and Language Disturbances. Grune and Stratton, New York.

9. Head, H. (1915): Hughlings Jackson on Aphasia and Kindred Affections of Speech. Brain, 38; 1-27.

10. Johnson, W. (1961): Measurements of Oral Reading and Speaking Rate and Dysfluency of Adult Male and Female Stutterers and NonStutterers.J. Speech Hearing Dis., Monograph Supplement No. 7, June; 1-20.

11. Johnson, W., Darley, F.L. and Spiestersbach, D.C. (1963): Diagnostic Methods in Speech Pathology, Harper and Row, New York.

12. Karlin, I.W., (1947): A Psychosomatic Theory of Stuttering.J. Speech Dis., $12 ; 319-322$.

13. Lanham, L.W., (1968): Lecture notes in Phonetics and Linguists II, University of the Witwatersrand. 
14. Lewis, D. and Sherman, D: (1951): Measuring the Severity of Stuttering. J. Speech and Hearing Dis., 16;320-326.

15. Luria, A.R. (1966): Higher Cortical Functions in Man. Tavistock Publications, London.

16. Newman, P.W. (1954): A Study of Adaptation and Recovery of the Stuttering Response in Self-formulated Speech. J. Speech Hearing Dis., $19 ; 450-458$.

17. Quarrington, B., Conway, J. and Siegel, N. (1962): An Experimental Study of some properties of Stuttered Words. J. Speech Hearing Res., 5; 387-394.

18. Reef, H. (1967): Apraxic Dysarthria.J. S.A. Logo. Soc., 14; 37-44.

19. Schaef, R.A. (1955): The use of questions to elicit Stuttering Adaptation. J. Speech Hearing Dis., 20; 262-265.

20. St. Onge, K.R. (1963): The Stuttering Syndrome. J. Speech Hearing Res., 6; 195-197.

21. Travis, L.E. (1931): Speech Pathology. D. Appleton and Co., New York and London.

22. Van Riper, C. (1971): The Nature of Stuttering. Prentice-Hall Inc., Englewood Cliffs, New Jersey.

23. Weisenburg, T.H. and McBride, E. (1935): Aphasia: A Clinical and Psychological Study. The Commonwealth Fund, New York.

24. Weiss, D.A. (1967): Similarities and Differences between Cluttering and Stuttering. Folia Phoniatrica, 19; 98-104.

25. West, R. (1958). An Agnostic's Speculations about Stuttering. In: Stuttering: A Symposium. Harper and Row Publishers, New York.

26. Wingate, H.E. (1967): Stuttering and Word Length. J. Speech Hearing Res., 10; 146-152.

27. Young, M.A. and Prather, E.M. (1962): Measuring the Severity of Stuttering using Short segments of Speech. J. Speech Hearing Res., $5 ; 256-262$. 